\title{
Diferentes Perspectivas na Análise da Interação Pais-Bebê/Criança
}

\author{
Cesar Augusto Piccinini ${ }^{2}$ \\ Universidade Federal do Rio Grande do Sul \\ Maria Lucia Seidl de Moura \\ Universidade do Estado do Rio de Janeiro \\ Adriana Ferreira Paes Ribas \\ Universidade do Estado do Rio de Janeiro \\ Cleonice Alves Bosa \\ Universidade Federal do Rio Grande do Sul \\ Ebenezer Aguiar de Oliveira \\ Malone College, EUA \\ Elizabeth Batista Pinto \\ Universidade de São Paulo \\ Ligia Schermann \\ Universidade Luterana do Brasil \\ Vera Lúcia Chahon \\ Universidade Federal Fluminense
}

\begin{abstract}
Resumo
Estudar a correspondência entre diferentes níveis de análise da interação pais-bebê/criança pode nos ajudar a chegar a uma linguagem mais comum e a compartilhar conceitos que permitam trocas mais frutíferas entre pesquisadores com diferentes orientações teóricas e metodológicas. Os autores do presente artigo representam alguns dos principais grupos de pesquisa brasileiros voltados à investigação da interação pais-bebê/criança. São apresentadas as diferentes perspectivas dos autores e discutidas as suas aproximações e diferenças, visando a demonstrar a complexidade e a diversidade de abordagens com relação às interações pais-bebê/criança e seu papel no desenvolvimento. Embora a definição de interação não seja consensual, verificase uma tendência entre os autores a considerar explicitamente a questão da ação recíproca, da co-construção e da bidirecionalidade. Não obstante o foco no comportamento manifesto e na ação recíproca existe também consciência de que as transações implícitas e as representações individuais e sociais influenciam a interação, e que há que se desenvolver procedimentos metodológicos rigorosos para estudá-las. Espera-se que a continuidade das discussões leve ao aprimoramento e à articulação das diversas propostas aqui apresentadas.

Palavras-chave: Interação mãe-bebê; co-construção; bidirecionalidade.
\end{abstract}

\section{Different Perspectives on the Parent-Infant/Child Interaction Analysis}

\begin{abstract}
Keywords: Parent-infant interaction; co-construction; bidirectionality.

${ }^{1}$ Endereço para correspondência: Instituto de Psicologia - UFRGS, Ramiro Barcelos 2600/111, Porto Alegre - RS. Fone: (51) 33165066, Fax: (51) 33309507.E-mail: piccinini@osite.com.br

'Os autores, com exceção de Adriana F. P. Ribas, são membros do GT da ANPEPP denominado Interação Pais-Bebê/Criança. As discussões que deram origem ao presente artigo se iniciaram em 1998, na reunião da ANPEPP, e no II Congresso Brasileiro de Psicologia do Desenvolvimento, em Gramado, RS, no qual os dois primeiros autores participaram do simpósio intitulado Diferentes paradigmas no estudo da relação pais-bebê. Em função disto, elaboraram a introdução e a discussão deste artigo. Os demais autores são apresentados em ordem alfabética.
\end{abstract}

The study of corresponding levels of analysis in the parent-infant/child interaction may lead us to a common language and shared concepts, that in turn will hopefully aid in the prolific exchanges among researchers from various theoretical and methodological backgrounds. The authors of this article represent some of the most prominent research teams of Brazil engaged in the study of parent-infant/child interaction. Their various perspectives are presented, as are their points of agreement and disagreement, with the purpose of demonstrating both the complexity and the diversity of approaches to the parent-infant/child interactions and their role in development. Although there is no consensual definition of interaction, there is a tendency of the authors to consider the question of reciprocal actions, co-construction, and bidirectionality. Granting that there is a trend to focus on manifested behavior and interaction, there is also a clear awareness that implicit transactions and social representations must be studied through rigorous methodological procedures, insofar as they influence interactions. It is hoped that, as these discussions progress, the ideas proposed herein will be both improved and better disseminated.

O estudo do desenvolvimento humano é uma das áreas mais importantes da Psicologia contemporânea. Nesta área as interfaces dos domínios intrapsíquico, interacional e intergeracional constituem um novo campo de pesquisa (Fivaz-Depeursinge e cols., 1994). Parece haver um certo consenso sobre a importância da interação social no desenvolvimento, mas há muito ainda que pesquisar. 
Uma das questões ainda pouco exploradas, apesar das discussões teóricas de autores como Vygotsky e Piaget, é a da relação entre níveis inter e intrapsicológicos, e a compreensão de processos de internalização ou interiorização. É importante que se examine qual a unidade mais apropriada em cada nível de descrição e quais as articulações entre estes níveis. Podemos examinar estas interfases a partir de diferentes perspectivas, como por exemplo, do ponto de vista de suas bases biológicas, de seus aspectos comportamentais, de sua origem sóciohistórica, de seus significados subjetivos e inconscientes e de suas raízes intergeracionais. Cada um destes níveis de descrição representa uma perspectiva de pesquisa diferente, com bases teóricas e conceituais e procedimentos metodológicos específicos e uma comunidade de pesquisadores que os adotam e os defendem. Em função disto, diferentes perspectivas se tornam, muitas vezes, incomensuráveis (Kuhn, 1970/ 1987), na medida que não há bases de comparação. Isto dificulta, e até inviabiliza, o diálogo entre diferentes pesquisadores e o avanço do conhecimento na área.

Estudar a correspondência entre diversas formas de análise da interação pais-bebê/criança pode favorecer a comunicação, o uso de uma linguagem comum e o compartilhar de conceitos, permitindo trocas mais frutíferas entre pesquisadores com diferentes orientações teóricas e metodológicas. Obviamente, este é um objetivo ambicioso, sendo este artigo uma tentativa inicial que, no mínimo, retrata a diversidade de conceitos e procedimentos de análise existentes na área.

Os autores do presente artigo representam alguns dos principais grupos de pesquisa brasileiros voltados à investigação da interação no desenvolvimento infantil. São pesquisadores de diferentes abordagens teóricas e metodológicas, que têm se dedicado à investigação dos fatores associados ao desenvolvimento infantil, da gestação aos primeiros anos de vida da criança. Eles fazem parte do grupo denominado Interação Pais-Bebêl Criança da Associação Nacional de Pesquisa e Pósgraduação em Psicologia - ANPEPP. Os simpósios da ANPEPP e outros encontros têm criado oportunidades para discussão de questões teóricas e metodológicas, e para o planejamento de ações conjuntas, no sentido de realização de pesquisas e da produção coletiva de conhecimentos na área.

Neste artigo, cada um dos autores foi solicitado a expor, sucintamente, os elementos de análise que considera essenciais na interação pais-bebê/criança, enfatizando os aspectos teóricos subjacentes, destacando: o nível de análise (ex. comportamento, linguagem, representação); o método (ex. descrição do comportamento, análise de relatos); a unidade (ex. categorias de comportamento, eventos interativos); e a duração dos segmentos (ex. 15 segundos).

O objetivo foi o de criar um espaço para se discutir e articular os diferentes níveis de entendimento sobre a interação pais-bebê/criança. Cada seção reflete a leitura particular que os autores fazem dos eventos interativos. Como cada seção é baseada em diferentes pressupostos teóricos, cada uma delas envolve enventos diferentes e modos específicos de analisá-los. Acredita-se que é nesta diversidade que reside a riqueza da proposta contida no presente artigo.

As seções serão apresentadas em seqüência, iniciando pelas propostas de análise da interação, que se baseiam, sobretudo, nos comportamentos e linguagem das díades, passando por aquelas que buscam articular os aspectos comportamentais e os subjetivos das interações, e terminando com as propostas que analisam, basicamente, as representações envolvidas nas interações. $\mathrm{Na}$ discussão final, buscar-se-á examinar eventuais correspondências entre as diferentes perspectivas de análise das interações, explorando-as sob o ponto de vista teórico e metodológico.

\section{Uma Perspectiva Sociocultural de Estudo das Interações Iniciais Mãe-Bebê}

Maria Lucia Seidl de Moura e Adriana Ferreira Paes Ribas

Para pensar o papel da interação no desenvolvimento, é necessário discutir o que se considera interação. Assumese aqui uma perspectiva que, acredita-se, está na própria raiz etimológica da palavra: inter-ação, "ação entre", o que implica em bidirecionalidade. Para o dicionário Aurélio (Buarque de Holanda, 1994): "Interação [inter + ação] 1. Ação que se exerce entre duas ou mais coisas, ou duas ou mais pessoas; ação recíproca". (p. 956).

Isto nem sempre tem sido levado em conta nos estudos psicológicos sobre a interação em psicologia do desenvolvimento, entre eles os de interação inicial mãebebê e de crianças pequenas. Nestes são freqüentemente usadas categorias de observação denominadas Socially Directed Behavior (SDB), ou seja, Comportamento Socialmente Dirigido, como, por exemplo, a mãe sorri para o bebê. As evidências relativas ao desenvolvimento inicial têm contribuído para a modificação deste quadro, tornandose crescente o interesse por um modelo bidirecional, caracterizado pela ênfase na reciprocidade e na adaptação mútua entre os parceiros (Bruner, 1996).

Esclarecida a questão do prefixo inter, resta ainda a da ação, que é talvez um problema bem mais complexo. Se for considerada a definição de ação como de ação externa, coordenada e intencional, talvez se excluam formas 
de influência recíproca. Afinal, Piaget nos demonstrou que as ações humanas se tornam gradualmente coordenadas, internalizadas e intencionais e, deste modo, é possível falar em ação não externa. Por outro lado, há problemas se a noção se ampliar demais. Isto fica claro na belíssima discussão entre Monod, Fodor e Inhelder, no debate entre Piaget e Chomsky, reproduzido parcialmente no livro editado por Piatelli-Palmarini (1980). Fica difícil, no desenrolar da discussão, distinguir ação de percep̧cão e a noção se esvazia.

A abordagem que Baltes e Staundiger (1996) propõem tenta lidar com a interação, levando em conta a ação não explícita, sem trivializá-la. Para esses autores, a expressão mentes interativas é uma metáfora interessante para discutir o papel da interação social na evolução e ontogênese da mente. Os autores incluem neste território conceitual transações externas e internas com representações mentais de outras pessoas.

Levando em conta a complexidade de definir interação, e sem qualquer pretensão de resolver esta difícil questão conceitual, adota-se em tese uma perspectiva que não abre mão do caráter recíproco da interação e que admite a possibilidade de formas de ação recíproca que não envolvam apenas ações explícitas. Isto, naturalmente, traz dificuldades metodológicas específicas para o tratamento empírico da questão, que também não se pretende resolver aqui.

As pesquisas do grupo Interação social e desenvolvimento (UERJ) sobre a gênese da interação social como constitutiva do desenvolvimento são orientadas pelos pressupostos acima e pela perspectiva sociocultural de tradição vygotskiana (Cole, 1998; Rogoff \& Chavajay, 1995). Assume-se nos diversos estudos empíricos do grupo uma posição conservadora e a seguinte definição de interação:

"O início de uma interação é caracterizado por um dos parceiros dirigir um comportamento social (atividade) em relação ao outro e ser respondido por ele com um comportamento social (atividade), num intervalo de 5 segundos. O fim do episódio de interação é caracterizado por um ou ambos os parceiros deixarem de dirigir comportamentos sociais (atividades) em relação ao outro por um intervalo de tempo maior que 5 segundos" (Seidl de Moura, 1999, pp. 19-20).

Esta definição parece satisfatória para o estudo da origem da interação social e para o período de desenvolvimento do bebê focalizado, mas sua generalização para investigações em outras etapas deve ser considerada com cautela. Para abordar a interação, são usados estudos observacionais com registro em vídeo, em que três conjuntos principais de categorias são alvo da análise: categorias de atividade dos parceiros, categorias de interação, categorias de contexto.

As atividade da mãe, definidas operacionalmente, incluem, entre outras: Gestos $(G)$, Vocalizações (V), Fala (F), Toque (T), Olhar o Bebê (OB), Mostrar Objeto (MO). As atividade do bebê, também definidas operacionalmente, incluem, por exemplo: Olhar o Ambiente (OA), Olhar a Mãe (OM), Tocar a Mãe (TM) e Vocalizar (V).

Visa-se a identificar instâncias de interação e tentativa de interação não efetivada. As categorias que compõem este grupo são: Domínio Social de Interação (DS), Domínio de Interação Mediado por Objetos (DMO) e Tentativa de Interação Não Efetivada (T). A categoria de interação foi definida acima. Os episódios de interação identificados são caracterizados em termos da ocorrência dos domínios.

O DS (Vibbert \& Bornstein, 1989) é identificado quando a mãe usa estratégias físicas e/ou verbais para engajar a criança interpessoalmente. O comportamento do bebê é também considerado, entendendo-se que o DS pode ser caracterizado se o bebê estiver dirigindo qualquer comportamento social em relação à mãe, desde que se mostre engajado com ela interpessoalmente (olhando, sorrindo, vocalizando, etc.).

A categoria de DMO também se origina na classificação de Bornstein e seus colaboradores (Vibbert \& Bornstein, 1989), sendo denominada de Dominio Didático. A terminologia foi modificada porque se considerou que dava a impressão de uma relação apenas de transmissão do adulto para o bebê, e não de uma constante negociação de significações e co-construção.

A Tentativa de Interação Não Efetivada (T) é caracterizada por um dos parceiros dirigir um comportamento social em relação ao outro e o outro não dirigir nenhum comportamento social como resposta, considerando um intervalo de cinco segundos entre os comportamentos. Para a análise dos episódios de tentativa são utilizados diversos critérios. As tentativas são importantes, porque revelam o engendrar das interações.

As categorias de observação do contexto visam a situar a caracterização das interações observadas. São elas: Contextos Específicos - cenários mais comuns de trocas entre as díades, incluindo, por exemplo, o de Amamentação e o de Cuidados do Bebế; Artefatos - transformações do ambiente físico acumuladas pelo grupo social no curso de seu desenvolvimento histórico (Cole, 1998); Scripts conjuntos de atividades que tendem a ser repetidas e que servem para especificar aos participantes de um evento os papéis sociais que desempenham, os objetos que são 
usados e as seqüências de ações exigidas (por exemplo, a maneira de dar banho em um bebê recém-nascido).

As observações são realizadas na residência das díades, em uma situação em que apenas a mãe e o bebê estão presentes, solicitando-se que a mãe mantenha sua rotina diária e ignore a presença do observador, na medida do possível. O registro em vídeo das atividades da mãe e do bebê é iniciado após alguma familiarização com o observador e tem duração variada. (20 minutos em estudos com bebês recém-nascidos e, atualmente, uma hora com bebês de cinco meses).

É utilizado na análise o registro por intervalos (Fagundes, 1985), através do preenchimento da Folha de Registro de Interação e Atividades (intervalos de 30 segundos). São então identificadas seqüências consideradas como instâncias de interação e de tentativa. Além disso, são também transcritas todas as falas e vocalizações da mãe durante a observação. Cada observação é analisada em termos da percentagem de ocorrências, em relação ao número total de intervalos da observação, das atividades da mãe e do bebê e das ocorrências de interação, nos diferentes domínios.

Além da comparação das atividades realizadas pela mãe e pelo bebê nos diferentes intervalos, seguida de uma análise qualitativa destas atividades, os episódios de interação e de tentativa de interação identificados são descritos e analisados qualitativamente, considerando aspectos como ajustes, por parte da mãe, no sentido de favorecer interações, entre outros. As falas e vocalizações da mãe durante a observação são analisadas em termos da atribuição de significado aos comportamentos do bebê e sua natureza. São, então, realizadas comparações entre as observações das diferentes díades, nos diversos aspectos estudados. Acredita-se que a perspectiva e a metodologia adotadas, aplicadas ao estudo de interações iniciais mãe-bebê, podem trazer contribuições significativas à compreensão do papel da interação no desenvolvimento.

\section{Perspectiva Co-Construtivista e Mediação Parental do Engajamento Infantil \\ Ebenezer Aguiar de Oliveira}

A interação social da criança com sua mãe (ou outro adulto) tem sido apontada como um importante mecanismo catalisador do desenvolvimento cognitivo por diversos autores, particularmente os adeptos da perspectiva sócio-histórica de Vygotsky (Brown \& Ferrara, 1985; Rogoff, 1998; Vasconcellos \& Valsiner, 1995; Wertsch, 1991). Tipicamente, analisa-se o papel mediador da mãe na promoção do nível cognitivo da criança dentro do que Vygotsky (1978) denominou de zona de desenvolvimento proximal. Ou seja, procura-se analisar as iniciativas e ações da criança e as correspondentes estratégias facilitadoras da mãe que levam a criança a atingir um desempenho desejável em uma tarefa que ela, sozinha, não teria condições de realizar com sucesso.

Dentro dessa perspectiva, portanto, o desenvolvimento é um processo de co-construção social, através de transformações e apropriações culturais pelas partes interagentes. Tarefas co-construtivas entre adultos e crianças tomam diversas formas na literatura, desde a simples montagem de uma fazenda de brinquedo (Elbers, Maier, Hoekstra \& Hoogsteder, 1992), ao compartilhamento do estado mental do outro para se encontrar uma barra de chocolate oculta (Sperb, 1999) e à leitura (Nogueira, 1993) ou composição (Smolka, 1993) de textos a partir de experiências dialógicas. Mas, para que a criança avance cognitivamente através da interação social, é indispensável que ela se mantenha engajada na tarefa. Geralmente, consegue-se isso ao se moderar o grau de dificuldade da tarefa, evitando a experiência de fracasso inicial. Mas, o que ocorre quando a dificuldade se acentua e o fracasso da criança é manifesto?

Ao contrário do que se acreditava até recentemente, Smiley e Dweck (1994) demonstraram que crianças pequenas podem exibir sintomas de desamparo aprendido (sentimentos negativos de frustração e expressões verbais de desânimo, ao ponto de abandonar uma tarefa), ao perceberem que fracassaram ou deixaram de atingir um objetivo explícito. Como desde a pré-escola o fracasso versus sucesso vem sendo individualizado por práticas pedagógicas normativas (Terigi \& Baquero, 1997), seria interessante estudar o papel mediador da mãe na manutenção do engajamento da criança numa tarefa coconstrutiva que se iniciasse com o fracasso. Pois é pela resistência à frustração que se mantém a chance de sucesso, em situações desafiantes (Oliveira, 2000; Smiley \& Dweck, 1994).

\section{Tarefa Co-Construtiva Frustrante}

Para estudar a resistência à frustração da criança e as estratégias mediadoras da mãe em busca da manutenção do engajamento infantil, eu e minha equipe de pesquisa temos empregado a tarefa de co-construção de uma casa de dois andares com lâminas de madeira, segundo uma maquete à vista (Oliveira, 2000). As cores das lâminas correspondem às das paredes e do telhado da maquete. Como as lâminas são muito delgadas, é preciso uma coordenação motora fina bastante desenvolvida para se conseguir manter as paredes de pé. Todas as crianças de quatro-cinco anos que tentaram cumprir essa tarefa sozinhas fracassaram, e a expectativa de sucesso com a ajuda da mãe é de aproximadamente cinco por cento, com base em observações anteriores.

Psicologia: Reflexão e Crítica, 2001, 14(3), pp. 469-485 
Cada sessão de interação da díade mãe-criança é gravada em videocassete individualmente, em uma sala da creche freqüentada pela criança. A tarefa proposta é constituída de quatro fases. $\mathrm{Na}$ Fase 1, que dura apenas dois minutos, a criança é instruída para tentar construir a casa sozinha. As Fases 2 e 3 duram três minutos cada. $\mathrm{Na}$ Fase 2, sem o conhecimento prévio da criança, a mãe é trazida para dentro da sala e é instruída para ajudar a criança apenas verbalmente; e, na Fase 3, ela é instruída a trabalhar fisicamente com a criança. Ao final da Fase 3, a experimentadora volta à sala e se desculpa por haver "esquecido" de entregar as bases de encaixe que sustentam as paredes. Ao receberem as bases, todas as crianças participantes completam com sucesso a tarefa na Fase 4, cuja duração é flexível.

Vale ressaltar que tanto as mães como as crianças só vêm a saber que falta uma peça fundamental para $o$ cumprimento da tarefa no início da Fase 4. Obviamente, isso faz com que as tentativas fracassadas nas fases anteriores gerem frustração tanto nas crianças como nas mães. O ponto de enfoque passa então a ser como as crianças manifestam sua frustração e como as mães ou agravam essa condição através da sua própria frustração (com críticas, por exemplo) ou, alternativamente, aliviam essa condição por meio de verbalizações de apoio.

\section{Detalhes Metodológicos}

Temos analisado vários aspectos comportamentais através desse modelo, empregando sistemas de codificação observacional também variados. De especial interesse para a presente discussão, analisam-se, por exemplo, as expressões emocionais e o engajamento da criança nas Fases 1 a 3 da tarefa. Pressupõe-se que esses comportamentos observáveis retratem processos internos, tais como a negatividade/positividade afetiva e a disposição de perseverar na tarefa a despeito do fracasso inicial. A vantagem de se examinarem esses aspectos através das três fases é que se pode comparar o efeito que a introdução da mediação materna (distal-verbal, na Fase 2; proximal-física, na Fase 3) traz à afetividade e ao engajamento da criança. Ou seja, pode-se ter uma idéia global da facilitação ou da interferência que a mãe passa a exercer quanto à regulação da frustração infantil na tarefa desafiante.

Empregamos o sistema de codificação em intervalo parcial fixo de cinco segundos para as expressões emocionais e o engajamento da criança, bem como para a cooperação diádica (na Fase 3). As definições das expressões emocionais são polarizadas entre positivas e negativas, mas não são mutuamente excludentes, envolvendo expressões universalmente relacionadas a

Psicologia: Reflexão e Crítica, 2001, 14(3), pp. 469-485 emoções específicas, tais como, lábios protuberantes para frente, olhar para baixo ou pelo canto dos olhos, testa franzida, sorriso, sobrancelhas em arco, etc. (Izard, 1993, 1996). Já o engajamento da criança é definido como o manejo de uma ou mais lâminas de modo a formar um ângulo maior que zero com a mesinha onde se tenta construir a casa, e a cooperação diádica envolve o manejo de uma ou mais lâminas contíguas pela mãe e a criança, ou o manejo concomitante de uma mesma lâmina pela mãe e a criança.

Esse modelo permite ainda que se analisem outros comportamentos mais relacionados às tentativas da mãe de manter a criança engajada. Por exemplo, podem ser registradas as freqüências relativas de várias verbalizações maternas, tanto de natureza didática (perguntas, demonstrações, diretivas, etc.) como de efeito emocional (elogios, críticas, etc.). Todas as codificações são feitas por dois codificadores cegos para os objetivos da pesquisa, sendo a confiabilidade dos escores obtida através da percentagem de concordância ou da correlação de intraclasse.

Enfim, através do modelo aqui apresentado enfocase o comportamento e/ou a afetividade da criança e da mãe, bem como da díade como uma unidade inseparável (cooperação diádica). Apesar da relativa artificialidade da tarefa em questão, o ambiente familiar em que se faz a filmagem e as precauções tomadas quanto ao estabelecimento de um bom rapport permitem-nos supor que os dados coletados podem iluminar futuras tentativas de se promover a resistência à frustração e o engajamento persistente em situações de grande desafio para a criança, além de contribuir para o entendimento do papel da interação no desenvolvimento infantil.

\section{Avaliação Quantitativa e Qualitativa da Interação Ligia Schermann}

No estudo do comportamento social, em especial da interação mãe-bebê, é possível utilizar diferentes métodos, separadamente ou em conjunto, os quais podem ser divididos em dois grandes grupos, conforme o tipo de abordagem da pesquisa - indireta ou direta (Schermann, Hagekull, Bohlin, Persson \& Sedin, 1997). Os métodos indiretos, como entrevistas, questionários e inventários, fornecem informações não só sobre o comportamento em si, mas também sobre atitudes, intenções e sentimentos subjacentes a ele. São dados usualmente retrospectivos e, no caso da interação mãe-bebê, baseados no relato da mãe (Bakeman \& Gottman, 1986).

Já os métodos que compõem a abordagem direta se caracterizam pela obtenção de dados durante a interação, a partir da observação do comportamento dos indivíduos 
envolvidos, o que permite maior proximidade com o objeto de estudo, bem como a obtenção de dados detalhados (Bakeman \& Gottman, 1986; Robson, 1993; Schermann, 1986). No entanto, a metodologia observacional é ampla e comporta vários enfoques, apresentando ao pesquisador diferentes níveis de escolha, quer referentes ao aspecto metodológico propriamente dito (o quê observar, quem e onde observar), quer referentes ao aspecto técnico (como observar e como registrar) (Schermann, 1999).

\section{Catálogos ou Protocolos de Observação}

Os catálogos ou protocolos de observação são compostos por unidades de comportamento, que necessitam de critérios objetivos para sua identificação e escolha de níveis de fragmentação. A divisão do comportamento em unidades pode ser feita a partir de mudanças em sua forma, designada como descrição física, topográfica ou morfológica; ou pode ser realizada pelos seus resultados e pelas suas conseqüências sobre o ambiente - descrição social ou funcional (Bakeman \& Gottman, 1986; Blurton Jones, 1981; Pellegrini, 1996).

No entanto, em ambas as formas de descrição - física ou social - o grau de fragmentação das unidades pode variar desde aquele resultante de movimentos simples, denominadas de unidades moleculares, até conjuntos comportamentais de ações amplas, chamados de unidades molares ou categorias, que envolvem uma variedade maior de movimentos, como brincar e chorar, dentre outras. (Batista, 1996).

O registro dos comportamentos pode ser feito através do uso de escalas referentes aos comportamentos em questão. As escalas podem ter por base a freqüência de ocorrência, bem como aspectos qualitativos de comportamentos socialmente definidos, como é o caso das escalas de sensitividade materna, desenvolvidas por Ainsworth, Blehar, Waters e Wall em 1978. O que importa é a definição precisa dos comportamentos e, no caso das escalas, de cada um dos níveis comportamentais mensurados (Schermann, Bohlin \& Hagekull, 1994).

O Protocolo de Observação da Interação Mãe-Bebê (0 a 6 meses) é um exemplo da análise da interação através do método de observação direta e registro do comportamento em forma de escala. (Schermann e cols., 1997). O Protocolo contem 21 itens, sendo 12 referentes ao comportamento da mãe e oito ao comportamento da criança durante a interação, bem como um item referente ao comportamento da díade (sintonia da interação). Os itens são pontuados em uma escala Likert de 5 pontos, em que escores mais altos equivalem à maior freqüência ou a um desempenho mais satisfatório.

Os itens da mãe podem ser agrupados em três categorias: sensitividade, intrusividade e envolvimento. Sensitividade materna aos sinais e comunicações do bebê pode ser mensurada como um aspecto geral do comportamento interativo materno, bem como através de itens específicos referentes à responsividade da mãe ao comportamento social e ao comportamento de estresse do bebê, e a qualidade de contato corporal. Escores altos de sensitividade refletem uma interação sintônica, caracterizada por um apropriado nível de resposta e de estimulação do bebê. Intrusividade diz respeito à ocorrência de comportamentos exagerados da mãe, como super-estimulação ou interferência inapropriada na atividade do bebê. O envolvimento materno é pontuado por medidas quantitativas referentes às comunicações verbais, contato ocular e atenção ao bebê.

A avaliação do comportamento interativo do bebê refere-se à freqüência da resposta aos comportamentos maternos e à intensidade dessa resposta, à tentativa de iniciar contato com a mãe, bem como à quantidade de sorrisos, vocalizações e contato ocular. O estado do bebê é mensurado pela quantidade de choro e pelo o humor geral demonstrado durante a interação. A variável diádica (sintonia da interação) é avaliada, de forma global, pela quantidade de interações positivas apresentadas pelo par mãe-bebê.

O Protocolo de Observação da Interação Mãe-Bebê (0 a 6 meses) tem sido utilizado para avaliar interações registradas em vídeo. Em nosso grupo de pesquisa, que se propõe a verificar o desenvolvimento de crianças que necessitaram de tratamento intensivo neonatal, procura-se filmar um grande número de crianças e suas mães durante a internação hospitalar, ou durante as consultas realizadas em ambulatório hospitalar de seguimento neonatal. As situações podem variar desde a tirada de roupa do bebê, situação de face-a-face, amamentação, ou uma tarefa mais específica, como a mãe brincar com o bebê utilizando brinquedos estipulados pelo examinador. Pode-se utilizar uma ou mais de uma situação durante a sessão de observação. O tempo da sessão igualmente pode variar, mas normalmente o utilizado por nosso grupo de pesquisa não ultrapassa a dez minutos para cada situação, sendo a pontuação realizada para cada situação como um todo. Devido à idade da criança, ela normalmente é colocada em decúbito dorsal, e a mãe situa-se em frente e acima, perpendicularmente à criança. A câmara filmadora é posicionada de forma a obter o melhor ângulo lateral do par mãe-bebê. Os observadores são treinados no uso do Protocolo e a fidedignidade do registro é verificada pelo teste de acordo entre observadores.

Este Protocolo de Observação tem sido amplamente utilizado por nosso grupo de pesquisa em estudos que procuram verificar o impacto do nascimento pré-termo e do risco médico neonatal nos comportamentos 
interativos do par mãe-bebê, partindo de pressupostos etológico-evolucionistas (Bowlby, 1984). Os dados obtidos através da observação da interação são complementados com dados da história familiar, gestação, parto e puerpério, cuidados dispensados com o bebê, rotinas e percepção da mãe sobre o seu bebê, além de avaliações pediátricas, neurológicas e desenvolvimentais do bebê (Alfaya, 2000; Schermann e cols., 1994; Schermann e cols., 1997). Os estudos realizados têm contribuído para a busca de compreensão das interações iniciais em situações de nascimento de risco. Acredita-se que a qualidade da interação inicial mãe-bebê é um importante fator mediador entre os eventos perinatais e o desenvolvimento sócio-cognitivo da criança.

\section{Observação da Interação Mãe-Criança e Transtornos do Desenvolvimento \\ Cleonice Alves Bosa}

O desenvolvimento sócio-lingüístico e da comunicação infantil depende, entre outros fatores, da qualidade da interação cuidador-criança (Carpenter, Nagell \& Tomasello, 1998). Alguns estudos têm demonstrado que mães de crianças com autismo tendem a ser afetadas pelo perfil bizarro de suas crianças podendo ser extremamente "diretivas" em seu estilo de interação, isto é, exercendo um intenso controle sobre a atividade da criança ou, ao contrário, retrair-se da interação (Trevarthen, 1996). A relação entre diretividade materna e desenvolvimento infantil tem sido amplamente investigada. Os achados parecem apontar para uma associação negativa entre diretividade materna e engajamento da criança em atividades interativas (Alvarenga, 2000). Por outro lado, a literatura em desenvolvimento apresenta evidências da relação entre a habilidade materna em seguir o foco de atenção/interesse da criança e desenvolvimento do vocabulário infantil (Carpenter e cols., 1998). Entretanto, os resultados na área de transtornos do desenvolvimento têm sido menos consistentes, tendo sido sugerido que o controle materno sobre as atividades da criança não implica necessariamente falta de resposta da criança (Bosa, 1998), e que a combinação entre diretividade e pouca sensibilidade aos sinais infantis é que poderia constituir-se num inibidor da atividade interativa mãe-criança (Marfo, 1990). Depreende-se desses achados que não há uma resposta final para a questão acerca do papel do estilo interativo diretivo para o desenvolvimento de crianças com autismo. Há portanto, a necessidade de investigação contínua desses aspectos, dadas suas implicações para intervenção.

A primeira versão do presente protocolo de observação foi desenvolvida para um estudo que buscou

Psicologia: Reflexão e Crítica, 2001, 14(3), pp. 469-485 investigar a relação entre afeto, comunicação e autoestimulação em crianças com e sem autismo (Bosa, 1998) e, mais tarde, adaptada para um outro estudo que investiga o efeito de estratégias de intervenção no comportamento de crianças autistas pré-escolares e no estilo de interação sócio-comunicativo de suas mães (em andamento), cujo procedimento será detalhado a seguir.

\section{Setting e material}

\section{Sessão Experimental}

A observação da interação mãe-criança ocorreu no Laboratório de Observação da Universidade Federal do Rio Grande do Sul, sendo constituído de uma sala e uma ante-sala entre as quais existe um espelho unidirecional para acompanhamento da sessão pelo experimentador. A sala era mobiliada com uma cadeira e um tapete sobre o qual estavam dispostos vários brinquedos escolhidos de acordo com a idade mental das crianças (avaliado com base em registros clínicos) e com os objetivos do estudo, tais como, telefone, instrumento musical, kit de aniversário e de médico, bicho de pelúcia, bonecos, carrinhos, blocos, tabuleiro p/ formas, e duas caixas transparentes com tampas difíceis de serem abertas pela criança (uma contendo biscoitos e outra, brinquedos coloridos e atrativos).

Estrutura da sessão, objetivos dos episódios e equipamentos utilizados

A sessão de observação constituiu-se de três episódios, cujo objetivo foi o de eliciar comportamentos sóciocomunicativos mãe-criança, envolvendo busca de assistência, compartilhamento de interesses e atividades (espontânea ou em resposta ao adulto) e estratégias maternas para engajar a criança em atividades. Os episódios foram: um de Brinquedo Livre, seguido por outro no qual a mãe era instruída a responder um questionário, sendo este precedido por outro episódio de Brinquedo Livre. Brinquedo Livre foi definido como uma situação de brinquedo entre a mãe e seu filho(a) na qual nenhum tipo de intervenção ocorre e nem qualquer exigência a respeito de como agir com a criança é feita à mãe. O episódio estruturado (em que a mãe responde a um questionário) visou a "retirar" a mãe da interação, a fim de se investigar a reação da criança quanto à busca pela retomada da interação. As caixas transparentes fechadas com tampas difíceis de serem abertas pela criança foram utilizadas para eliciar comportamentos de busca de assistência do adulto. Cada sessão foi de, aproximadamente, 30 min e foi filmada para posterior análise, utilizando-se duas câmeras de vídeo, localizadas em cantos diagonalmente opostos da sala, e ocultas por cortinas. Equipamentos de edição foram utilizados na mixagem das imagens. 


\section{Comportamentos Sócio-Comunicativos}

As definições operacionais dos comportamentos sócio-comunicativos infantis e maternos foram traduzidas do protocolo de Bosa (1998) e adaptados para o presente estudo, o qual examinou também o tipo de brinquedo e maneirismos motores (não apresentados nesse trabalho). Para o desenvolvimento das categorias infantis e maternas tomou-se como referência a literatura na área da pragmática evolutiva, particularmente os estudos de Bates, Camaioni e Volterra (1979), cujos pressupostos teóricos encontram-se melhor detalhados em Bosa (no prelo). A premissa básica dessa abordagem é a análise da comunicação mãe-criança a partir do contexto social em que ocorre, focalizando tanto a linguagem verbal quanto a não-verbal (gestos e direção do olhar).

Os comportamentos maternos observados foram divididos nas seguintes áreas: a) comportamento verbal materno para engajar a criança em atividades, composto por diferentes modalidades de perguntas, comentários, comandos e reprovações; b) comportamento gestual; c) direção do olhar; e d) manipulação de objetos. Diretividade Materna foi definida como a combinação das categorias "comandos" e "reprovações", assim como diferentes categorias de "comentários" foram combinadas para designar o comportamento materno focalizado em atividades da criança. Os comportamentos infantis foram: a) iniciativa em buscar o adulto (pedidos, atenção compartilhada, verbalização, etc.); b) respostas às solicitações do adulto (executa, ignora, olha, protesta, etc.); e direção do olhar.

A codificação é feita utilizando-se um computador, cujo teclado pode ser adaptado para o registro de ocorrência dos comportamentos observados, e um software (Repp e cols., 1989), além de um espaço para anotações. O custo deste aparatus é mínimo e adequado às limitações de recursos do projeto. $\mathrm{O}$ tipo de registro escolhido foi por intervalo (10 segundos). A freqüência de cada comportamento investigado foi dividida pelo tempo de observação, fornecendo uma taxa. As categorias são exclusivas e exaustivas. Dois observadores, 'cegos' em relação aos objetivos do estudo, são treinados para a codificação dos comportamentos. A fidedignidade entre os observadores é calculada, utilizando-se três minutos dos videotapes.

O sistema de codificação por intervalos é útil e rápido, quando se lida com um grande número de díades ou horas de observação. Outra de suas vantagens é que fornece informações sobre como as díades utilizaram o tempo de interação, possibilitando informações sobre a seqüência dos comportamentos examinados. A principal limitação é a ocorrência de uma certa interrupção no fluxo da interação, já que os comportamentos são exclusivos e exaustivos, nem sempre refletindo o que de fato ocorreu (ex: uma escolha deve ser feita se mais de um comportamento do mesmo grupo ocorreu no mesmo intervalo).

Enfim, a escolha do tipo de codificação a ser empregado parte das bases epistemológicas do pesquisador e da natureza investigativa do seu estudo. $\mathrm{O}$ modelo aqui apresentado tem sido útil na investigação de processos interativos na área dos transtornos do desenvolvimento.

\section{Aspectos Subjetivos e Comportamentais da Interação Mãe-Bebê/Criança \\ Cesar Augusto Piccinini}

A importância de se estudar o apego mãe-bebê reside nas suas conseqüências para o desenvolvimento emocional da criança e, em particular, para a sua socialização. A teoria do apego (Bowlby, 1969/1984), constitui-se num dos enfoques mais expressivos no estudo do processo de interação mãe-bebê e tem sido um dos mais utilizados em nosso grupo de pesquisa. Para Bowlby, os comportamentos que compõem um dado padrão de apego operam segundo um "modelo interno de funcionamento", construído a partir da relação com a figura de apego no início da vida e guiam as relações futuras. $\mathrm{O}$ apego envolve uma relação de cunho afetivo para com a mãe, que leva o bebê a procurar a presença e conforto maternos, particularmente, quando se sente assustado ou inseguro (Ainsworth, Blehar, Waters \& Wall, 1978). Segundo a concepção etológico-evolucionária da teoria do apego, o neonato nasce com certas tendências instintivas (comportamentos de sugar, mamar, agarrarse, seguir com os olhos e chorar), cuja função é chamar a atenção da mãe e estimular uma resposta materna.

Embora o bebê humano venha ao mundo programado para apegar-se a um cuidador, é necessário que este seja responsivo e disponível para que se desenvolva um padrão de apego seguro (Bowlby, 1969/ 1984; Brazelton, 1988). O trabalho de Ainsworth e colaboradores (1978) foi fundamental na identificação dos diferentes padrões de apego, principalmente através da Situação Estranha, procedimento experimental especialmente desenvolvido para este fim (Lopes \& Piccinini, 1992). O estabelecimento de distintos padrões de apego vai depender, em grande parte, da sensibilidade materna às necessidades infantis, assim como da capacidade da criança de usar a mãe como base segura, a partir da qual explora o mundo e para onde retorna quando em situação de perigo ou angústia.

Psicologia: Reflexão e Crítica, 2001, 14(3), pp. 469-485 
Até recentemente, a maioria dos muitos estudos sobre interação mãe-bebê examinaram fatores referentes ao papel da mãe neste processo, enquanto menos atenção foi dada às contribuições da criança (Bosa \& Piccinini, 1994). Além disto, muitos pesquisadores não se preocuparam com a questão da reciprocidade na interação, talvez em função dos estudos de pioneiros como Spitz (1965/1998), que por vezes descreviam o bebê como um ser passivo. Considerando a bidirecionalidade como inerente ao conceito de interação, este processo tem sido entendido mais recentemente como tendo base em um sistema de comunicação, caracterizado por seu ritmo, sincronia, ajuste mútuo e, sobretudo, reciprocidade (Carvalho, 1988; Tronick, 1989). As contribuições maternas e infantis dificilmente podem ser dissociadas ao se estudar a díade em interação, e é importante que se contextualize a contribuição de cada membro da díade e da própria díade como parte de outros contextos sociais. Apesar de avanços conceituais, muitos estudos têm se restringido a examinar os comportamentos de uma das partes da díade em interação, tendo em vista a dificuldade e a complexidade de se utilizar propostas mais sofisticadas, como análise seqüencial. Além disto, o comportamento materno, em geral, constitui-se no primeiro contexto para o desenvolvimento do bebê, e por isto, continua merecendo atenção especial.

Partindo de estudos realizados pelo nosso grupo que investigavam apego mãe-bebê, examinando separadamente comportamentos da mãe e do bebê (Ainsworth e cols., 1978), passou-se, nos últimos anos, a investigar a qualidade da interação mãe-bebê através de conceitos envolvendo, de alguma forma, a bidirecionalidade da interação. Mais recentemente, passou-se também a examinar as verbalizações parentais sobre a interação com o bebê, buscando compreender o significado particular e subjetivo que cada bebê e seus comportamentos tem para seus pais. Descrevem-se, a seguir, alguns destes procedimentos de análise de dados utilizados em nosso grupo para investigar as interações mãe-pai-bebê/crianças pequenas. As situações de interação têm sido sempre filmadas (durante períodos de trinta a quarenta minutos), sejam elas realizadas na sala de brinquedos da universidade, na residência da família ou em hospitais, quando investigamos mãe-bebê pré-termo. A idade da criança varia desde bebê pré-termo até crianças com três anos. De modo geral, temos analisado categorias de comportamento em intervalos de tempo de 15 segundos, utilizando-se uma amostra do tempo filmado, usualmente seis minutos. Em alguns estudos utilizou-se também da análise de evento de interação, quando se examinou o tipo, freqüência e duração de cada evento investigado.
Um dos procedimentos que se tem utilizado para examinar apego mãe-bebê, com crianças de 18 meses, é a Situação Estranha (Ainsworth e cols., 1978), composta de episódios de interação mãe-criança e criança-estranho, realizada numa sala de brinquedos na universidade. Em cada intervalo de tempo examina-se a freqüência de comportamentos do bebê (manipulação e locomoção exploratória, olhar, vocalização, sorriso e choro) e a intensidade de comportamentos interativos (busca de contato e proximidade, manutenção de contato, interação à distância, resistência e esquiva), numa escala que varia de intensidade mínima à intensa e persistente.

Com bebês nos primeiros três meses de vida temos examinado a interação através da incidência dos comportamentos do bebê (Ex.: vocaliza, chora/agitado, olha para mãe, alerta/quieto, sonolento/dorme, comportamentos involuntários) e da mãe (Ex.: interpreta/ fala pelo bebê, responde à vocalização ou choro do bebê, fala pelo bebê, olha o bebê, sorri para o bebê, embala/ aconchega o bebê, acaricia o bebê, estimula o bebê, posiciona face-a-face o bebê) em interações livres e situação de banho na residência da família. Já com bebês pré-termo mantidos na incubadora, cujos comportamentos manifestos são pouco variados, optouse por examinar somente os comportamentos maternos antes e após uma intervenção que visava a aumentar a interação mãe-bebê.

Mais recentemente, passou-se a enfatizar a bidirecionalidade das trocas que ocorrem numa interação, examinando, por exemplo, a contingência dos comportamentos mãe-criança que busca identificar os antecedentes e conseqüentes de cada comportamento (Ex.: mãe $\rightarrow$ criança $\rightarrow$ mãe ou criança $\rightarrow$ mãe $\rightarrow$ criança). Ao final de cada intervalo de tempo, registra-se o último comportamento (da mãe ou da criança) e busca-se o seu antecedente. Um outro procedimento utilizado em nosso grupo com bebês no primeiro ano de vida é o exame da incidência de interações sincrônicas e assincrônicas (Wendland-Carro, Piccinini \& Millar, 1999), registrandose, em cada intervalo de tempo, a presença destas seqüências sincrônicas mãe-bebê (ex. vocaliza $<\longrightarrow>$ olha, olha $<\longrightarrow>$ sorri, chora $<\longrightarrow>$ embala) e assincrônicas (ex. chora $<\longrightarrow>$ não responde, vocaliza $<\longrightarrow$ não responde, comportamento involuntário $<\longrightarrow$ não responde).

Também se considera importante examinar os aspectos subjetivos da interação, investigando as representações, memórias e significados associados ao bebê e situações que o cercam. Além da observação das interações diádicas (mãe-bebê e pai-bebê) e triádicas (mãepai-bebê), têm-se examinado, através de entrevistas estruturadas e tópicas, os relatos tanto de gestantes e 
futuros pais, como de mães e pais em vários momentos do desenvolvimento do seu filho(a). Durante a gestação, investigam-se tanto aspectos transgeracionais através do genograma de cada genitor, a história do casal, sonhos e sentimentos durante a gestação, o bebê imaginário, assim como as expectativas e sentimentos em relação à interação com o bebê. Após o nascimento, tem-se examinado o relato de mães e pais em diversos momentos do desenvolvimento do bebê, investigando-se os seus sentimentos sobre o parto e o bebê real, seu jeito de ser mãe/pai, o temperamento do bebê, participação de cada genitor nos cuidados do bebê, transição do casal para a família, expectativas e valores parentais sobre o futuro da criança e práticas educativas, entre outros temas.

Nossa tentativa tem sido a de integrar estas diversas abordagens metodológicas com vistas a melhor investigar a qualidade da interação mãe-bebê. De qualquer modo, acreditamos que o melhor método para examinar a interação depende, principalmente, da questão de pesquisa sendo investigada (Beslky, 1986). Além disto, nem sempre é viável se utilizar determinados tipos de análise (ex. seqüencial), seja pela sua complexidade, seja porque o bebê, em algumas situações, como as envolvendo prematuridade, reage inicialmente muito pouco às iniciativas maternas de interação. Por fim, todos os nossos estudos envolvem sempre grupos de comparação (ex. temperamento difícil versus fácil, asmáticos versus cardíacos; comparação entre diferentes intervenções), mesmo quando envolvem estudos de casos múltiplos. A análise da interação constitui-se de um indicativo de eventuais diferenças entre os grupos que corroboram ou não as expectativas teóricas iniciais.

\section{Contribuição para a Análise das Interações Precoces na Perspectiva Psicanalítica \\ Elizabeth Batista Pinto}

Diversos autores entre os quais Melanie Klein, René Spitz, Donald Winnicott e John Bowlby, contribuíram para o desenvolvimento dos conhecimentos teóricos básicos sobre as interações precoces, em particular entre a mãe e o bebê. Considerando a abordagem psicanalítica, seguindo os pioneiros como Fraiberg (Fraiberg, 1980; Fraiberg, Adelson \& Shapiro, 1976) em São Francisco, Lebovici (1983, 1992 e 1994) em Paris, Cramer (1974, 1985, 1987 e 1988) e Palacio-Espasa (Cramer \& PalacioEspasa, 1993) em Genebra, nos últimos anos vários outros estudos (Cramer, 1997, 1999; Golse, 1998; Guedeney \& Lebovici, 1999; Lebovici, 1998; Mazet, 1999; Mazet, Cukier-Hemeury, Latoch, Rosenblun \& Sitbon, 1989; Mazet \& Stoleru, 1990;) sobre as interações precoces foram publicados.
Pesquisas provenientes de outras abordagens teóricas como a Psicologia do Desenvolvimento, a Psicologia Cognitiva-Construtivista e a Psicologia Sistêmica, também têm sido importantes para o desenvolvimento dos conhecimentos sobre a interação mãe/criança e o vínculo precoce, destacando-se as contribuições também pioneiras de Ainsworth (Ainsworth, Bell \& Stayton, 1974; Ainsworth, Blehar, Waters \& Wall, 1978), Brazelton (Brazelton, 1981; Brazelton \& Als, 1981), Stern (1977, 1985, 1997), Field (1987) e outros.

Esses estudos, que podem apresentar complementaridades e divergências, e se basearem em diferentes parâmetros qualitativos e quantitativos e em situações naturais, experimentais, clínicas - diversas, têm em comum a consideração da importância da interação mãe/bebê para a constituição do vínculo primário, fundamental para o desenvolvimento psíquico da criança. Pretende-se com este artigo contribuir com elementos para a análise das interações precoces, tendo por base a abordagem psicanalítica, considerando-se conhecimentos de estudos e pesquisas de outras áreas que foram assimilados e que são compatíveis com esta orientação.

Pode-se definir interação como "a reação recíproca de dois fenômenos" (Mazet e cols., 1989, p.19), acentuando-se a noção de reciprocidade e interdependência entre eles, e partindo-se do princípio que a relação do bebê com o círculo maternante se dá em um processo bi-direcional. A interação é considerada então, de forma geral, como um processo constituído por um "conjunto de fenômenos dinâmicos que ocorrem ao longo do tempo entre o bebê e sua mãe" (Mazet e cols., 1989, p. 20).

Nesse processo interativo, o bebê não é apenas submisso às influências do ambiente, mas é também um parceiro ativo, que gera importantes modificações no seu meio, cabendo ao círculo maternante interpretar as suas necessidades físicas e psíquicas, e contribuir no sentido de atende-las, favorecendo a regulação dos estados e a organização dos sistemas de biorritmo. Portanto, a interação se dá em um interjogo entre parceiros, no qual um influencia o outro em um processo contínuo de desenvolvimento, a partir de mecanismos de regulação recíproca.

Considera-se assim que a interação entre o bebê e o adulto é sempre assimétrica, permanecendo, no início, principalmente não-verbal, o que dificulta sua análise, compreensão e interpretação. Cada um dos participantes da interação tem manifestações que dependem do seu próprio funcionamento psíquico: a mãe, o bebê e também o pai. Isto significa que, como em qualquer relação interpessoal, além das pessoas diretamente envolvidas, com suas características reais, há elementos representacionais imaginários e fantasmáticos.

Psicologia: Reflexão e Crítica, 2001, 14(3), pp. 469-485 
As representações englobam as fantasias, os temores, os desejos, as distorções, as percepções seletivas atribuídas, etc. de cada um dos parceiros da díade, ou da tríade, com relação ao outro, estando implicados tanto os elementos imaginários, acessíveis ao consciente, como os elementos fantasmáticos e as identificações inconscientes. São principalmente as relações familiares que regulam a corrente emocional, influenciam a eleição de defesas e modelam o alcance do impacto fantasia/realidade na criança sendo as interações reais um correlato das interações fantasmáticas (Cramer, 1974).

O apego, definido por Bowlby (1982) como a propensão dos seres humanos a estabelecerem fortes vínculos afetivos com outros e de explicarem as diferentes formas de consternação emocional que ocorrem quando da separação ou perda involuntárias do outro, é construído a partir do processo de interação entre o bebê e o círculo maternante. Os aspectos psíquicos da mãe e do pai, ou seja das pessoas que formam o círculo maternante, e principalmente seus recursos internos de resiliência, são elementos fundamentais implicados na relação com a criança, e sua consideração deve levar em conta a história dos pais enquanto crianças e filhos de seus próprios pais. Esta é a dimensão transgeracional das representações, que tem registros em cada um dos protagonistas, nas suas relações e na dinâmica familiar.

A família, considerada como unidade social básica, forma como que uma membrana semi-permeável entre seus membros e o grupo social, sofrendo pressões de diversas naturezas (costumes/normas, forças históricas, etc). No entanto, se a influência direta dos pais persiste na vida por um tempo limitado, sua influência afetiva e estruturante pode influir por toda a vida, e seu registro psíquico transcende sua presença física e mesmo sua morte, podendo elementos das relações estabelecidas influenciarem gerações posteriores em uma transmissão transgeracional, a qual se dá, principalmente, de forma inconsciente. Os distúrbios precoces da interação ocorrem por aspectos ligados ao adulto e suas representações, e por elementos da criança que repercutem no adulto e nas representações deste.

Assim, os padrões de parentalidade podem ser identificados e a dinâmica interativa compreendida a partir dos distúrbios emocionais dos pais e da criança, podendose analisar as interações em seus diferentes aspectos, buscando-se uma compreensão ampla e abrangente, procurando o sentido latente que os distúrbios possam ter na dinâmica familiar, seu sentido na história pessoal dos protagonistas, seu registro nas relações atuais e sua dimensão transgeracional. $\mathrm{Na}$ análise das interações precoces, principalmente mãe/bebê, há elementos básicos

Psicologia: Reflexão e Crítica, 2001, 14(3), pp. 469-485 a serem considerados: os padrões de parentalidade e a dinâmica interativa.

Quanto aos padrões de parentalidade devem ser valorizados os elementos saudáveis, enfatizando-se os aspectos positivos como os pais desempenham suas funções centrais de defesa da vida e da saúde, de cuidados físicos, de promoção de experiências iniciais, de favorecimento do desenvolvimento físico e psíquico, de transmisssão e criação de normas culturais e de educação até o indivíduo ter condições para uma vida independente. Devem ser identificados também os aspectos associados à parentalidade patogência, seja por omissão, depreciação, rejeição, descontinuidade, abandono etc... que podem conduzir a desajustes e a sintomas psicofuncionais na criança ou psicopatologias mais graves.

Quanto à dinâmica interativa esta deve ser considerada a partir de três eixos principais: A interação comportamental, que inclui aspectos diretamente observáveis: as ações - a maneira como o bebê é cuidado, segurado e manipulado nas atividades de rotina e de interação; as interações corporais - toque, contato cutâneo, movimento corporal, carícias, exploração do corpo, ajustes posturais e motores; as interações visuais - contato visual, interação face-a-face; as interações vocais - fala, entonação, linguagem, canto, choro, riso; os ciclos de interação, incluindo o emparelhamento e a sincronicidade - alternância de respostas e dos ciclos de atenção e desligamento, trocas de papéis, reciprocidade, controle no ritmo interativo.

A interação afetiva, que envolve os afetos e suas formas de expressão: a atenção e a sensibilidade aos sinais da criança - interpretação dos sinais, intensidade da estimulação, qualidade das respostas, escolha de atividades adequadas levando em conta a idade, as condições e o desenvolvimento da criança assim como a situação; a responsividade, a reciprocidade e os intercâmbios respostas apropriadas em tempo compatível, mutualidade harmônica; a tonalidade emocional dominante nas trocas afetivas - sentimentos manifestos no comportamento, no contato corporal, na linguagem e na comunicação em geral, o compartilhar das experiências emocionais, a estabilidade das manifestações afetivas e a sincronia com a situação, a harmonia nas trocas afetivas; as transformações da interação - acompanhando o desenvolvimento físico e psíquico do parceiro.

A interação fantasmática, que considera os aspectos intrapsíquicos (Cramer, 1974), incluindo a dimensão transgeracional: as expectativas, fantasias e identificações da mãe e do pai com relação à criança - sexo, aparência física, nome, saúde, comportamento etc.; a percepção da mãe e do pai de si próprios, como pais e como pessoas, e de seu parceiro conjugal, como pai/mãe e como 
pessoa; a percepção da mãe e do pai de seus próprios pais, como pais e como pessoas; as mudanças nas relações dos pais com as próprias mães e pais a partir do nascimento da criança.

As interações precoces podem ser analisadas a partir de situações diversas, como a observação direta em situação natural (Bick, 1968), a observação clínica em consulta terapêutica (Mazet \& Stoleru, 1990), as técnicas estruturadas como roteiros de entrevista (Entrevista "R" de Stern, Robert-Tissot, De Muralt \& Cramer, 1989), os questionários específicos (Symptom Check-list de RobertTissot, 1989), a aplicação de escalas de desenvolvimento (Escala do Desenvolvimento do Comportamento da Criança no Primeiro ano de Vida, Batista Pinto, Vilanova \& Vieira, 1997), as situações controladas (Kia Profil de Stern, Robert-Tissot, De Muralt \& Cramer, 1989) e outras. Para o registro das interações o vídeo tem-se mostrado uma forma eficiente, que favorece diversos tipos de análise e a memória para posterior recuperação dos dados (Acoca Trigano, 2000).

Concluindo, a análise das interações precoces tem-se mostrado um instrumento muito rico na intervenção psicológica na dinâmica familiar (Batista Pinto, 2000), possibilitando a detecção precoce de conflitos relativos à maternagem e à paternagem, favorecendo a interpretação, e contribuindo para prevenir distúrbios do vínculo com suas conseqüências no desenvolvimento da criança e no aparecimento de sintomas psicofuncionais e psicopatologias.

\section{Observando Bebês pelo Método Psicanalítico: Delicada Intimidade \\ Vera Lúcia Chahon}

Os bebês sempre estiveram ao alcance de nossos olhares, entretanto, pode-se dizer que coube à psicanálise dar um passo significativo ao colocar ênfase na importância dos primórdios da vida infantil para o desenvolvimento do indivíduo. Considerar os bebês como seres humanos dotados de sentimentos e emoções complexos, é algo muito recente na história da humanidade, fato que vem suscitando cada vez mais a necessidade de aprofundar conhecimentos sobre o funcionamento mental infantil.

Há quase um século, Freud (1905), ao escrever seus Três Ensaios sobre a Sexualidade Infantil, asseverou que: "Se a humanidade pudesse aprender pela observação direta de crianças, estes três ensaios não precisariam ser escritos" ( $p$. 13). Embora não trabalhasse com crianças, encorajava amigos e discípulos a observarem no cotidiano o desenvolvimento de seus filhos, tendo estas recomendações resultado no importante trabalho sobre o caso clínico do pequeno Hans (Freud, 1909).
Os idos anos 70 marcaram uma época de muita fertilidade em que proliferaram trabalhos referentes ao estudo do universo do recém-nascido em diferentes países, privilegiando a multidisciplinaridade. O bebê passou, então, a surpreender pela descoberta de suas capacidades desde os tempos mais remotos de seu existir. Muitos são os pesquisadores e estudiosos, dentre eles psicanalistas e psicólogos do desenvolvimento, que vêm contribuindo significativamente para o entendimento da primeira infância, através de diferentes métodos de observação das interações pais-bebê-criança, favorecendo, deste modo, uma transformação nas relações entre a psicanálise e a psicologia do desenvolvimento. Destacam-se, neste aspecto, os trabalhos de Brazelton (1962, 1974) e Stern $(1977,1992)$ que colaboraram para a vinculação de estudos do desenvolvimento com a psicanálise.

O intuito deste trabalho é focalizar a valiosa contribuição dada por Esther Bick, ao introduzir, em 1948, na Clínica de Tavistock, seu método de Observação Psicanalítica da Relação Mãe-Bebê (ORMB), com o objetivo de treinar psicoterapeutas de crianças. Posteriormente, esta técnica foi introduzida como parte do curso de formação de psicanalistas na Sociedade Britânica de Psicanálise e se estendeu para outros institutos de formação por todo o mundo. Inicialmente voltado para a formação clínica, este método veio ganhando terreno e, na atualidade, inúmeros são seus desdobramentos e aplicações em contextos que se estendem para além do campo estritamente clínico.

Em seu artigo Notas sobre a Observação do Bebê na Formação Psicanalitica, Esther Bick (1964) detalhou o método que aqui abordamos de modo abreviado. Trata-se da observação direta de um bebê recém-nascido, em seu ambiente natural, entendido como seu contexto familiar, ao longo de seus dois primeiros anos de vida. Em alguns institutos de formação, o tempo de duração da observação foi reduzido para um ano.

O observador deve estabelecer contato com os pais durante o período de gestação, de modo a garantir que logo após o nascimento as visitas possam ocorrer semanalmente, com a duração de uma hora, em dia e horário previamente acordados. Este tipo de contrato visa a estabelecer e preservar uma certa regularidade de participação do observador junto à dupla/tríade. Logo após a visita, o material observado deve ser descrito em seus mínimos detalhes, sem discriminação, incluindo as vivências e sentimentos do observador diante dos movimentos da dupla/tríade. A linguagem utilizada deve ser coloquial e isenta de quaisquer formulações teóricas, de modo a resultar em relatórios semanais a serem lidos e discutidos no grupo de supervisão. 
O estreito vínculo deste método com o método de observação em psicanálise foi suficientemente explorado por Shuttleworth (1995) e Houzel (1995), que estabeleceram um contraponto com os modelos tradicionais da pesquisa experimental. Estes autores apontaram para a característica distintiva do modelo de Bick, que não comporta qualquer hipótese de trabalho aprioristicamente e não privilegia nenhum foco específico. Freud (1914) aconselhava a postura de 'cegar-se' artificialmente, de modo que todo o foco pudesse ser conduzido no sentido de iluminar um ponto obscuro. A este respeito disse: "Aprendi a controlar as tendências especulativas e a ... olhar as mesmas coisas repetidas vezes até que elas comecem a falar por si mesmas" (p. 33).

$O$ interesse de observar a mente humana em sua expressão no relacionamento humano constitui mais um de seus elos com a psicanálise. Couto Rosa (1995) afirmou que:

"Tanto numa situação como na outra, o que observamos seriam produtos transformados e não a 'coisa em si'. Até mesmo quando estamos diante de uma comunicação verbal. Sabemos que nem sempre são as palavras, em seu conteúdo imediato que irão produzir a revelação, já que também elas são transformações à espera de serem reconhecidas no domínio do relacionamento humano que caracteriza a prática analítica" (p. 301).

No modelo proposto por Bick (1948), o que se observa é a singularidade de cada conjunto pais-bebê, a delicadeza dos detalhes, das emoções, dos encontros e desencontros, procurando-se respeitar e preservar as peculiaridades de cada ser humano envolvido e de cada conjunto em particular.

Baseada nesses estudos e no treinamento pessoal em ORMB e com a perspectiva de conjugar a experiência docente aliada à formação de psicanalista, foi que demos início em 1997, na Universidade Federal Fluminense, a um trabalho de pesquisa voltado para a observação da relação mãe-bebê segundo o método de Esther Bick. Como supervisora de Estágio em Psicologia Clínica e em face de uma demanda crescente de atendimento a crianças cada vez mais jovens, nosso objetivo visava tanto à formação do psicólogo clínico, como a aprofundar os estudos sobre o desenvolvimento infantil . Dentro deste espírito, adotamos a metodologia preconizada por Bick (1948) que se assenta sobre três eixos interligados, constituídos pela interação mãe-bebê-família, pelo observador e pelo grupo de seminário. Embora nosso intuito aqui não seja proceder ao estudo de casos, cabe tecer breves comentários relativos às vivências do alunoobservador-pesquisador e à importância do seminário em grupo.
A proposta de observar um bebê em seu contexto familiar, por um longo período de tempo, gera uma série de fantasias no observador, geralmente expressas no grupo de supervisão. Mélega (1995) foi feliz ao sintetizar essas vivências tão comuns no observadorparticipante:

"O receio de ser invasivo, ao se introduzir na família para 'ver' uma cena da intimidade da relação da mãe com seu bebê, é uma das questões. Ver! Consciente de que está lá interessado em ver e manifestando seu desejo de ver para conhecer. Sem disfarces, sem subterfúgios! Sem o escudo de outros papéis... É a legítima busca de conhecimento! Esta clareza de propósitos assusta o observador! Expõe-se para conhecer a 'cena'e expõe-se para ser conhecido - por si mesmo e pelos outros! O receio de ser invasivo é a contrapartida do receio de ser invadido " (p. 265).

Essa técnica implica, também, preparar o aluno para se aproximar e suportar o encontro de vários outros seres se relacionando e, a partir daí, poder chegar a algum conhecimento, mesmo que para isto tenha que aguardar algum tempo. Cabe a ele preparar-se para receber tudo o que vier, preparar-se para o inesperado, mantendo uma atitude de espera e abstenção. O observador está incluído necessariamente no processo da observação e, assim, sua presença percebida pela mãe e/ou pelo bebê poderá ser usada para compartilhar toda sorte de sentimentos, seja através da linguagem verbal ou não. Caron (1995) afirmou ser este um papel fundamental e necessário, perseguido em qualquer fase da vida. Segundo ela, é comum que as mães façam uso dessa presença para liberar o que nelas se encontra contido. Podem, a partir daí, atribuir significado às próprias emoções.

Da mesma forma que o observador pode ocupar o lugar de continente das angústias e ansiedades primitivas, também o grupo de supervisão desempenha para o aluno uma função semelhante e de inestimável valia, na medida em que ajuda a conter angústias advindas do contato com a dupla, permitindo a continuidade das visitas e promovendo a reflexão sobre sua participação no processo. É também tarefa do grupo estimular a pensar, constituindo-se em um espaço onde se pode chegar através da escuta, à revelação dos significados do material apreciado em supervisão.

O trabalho de ORMB realizado na esfera acadêmica vem apontando para a importância deste método em suas várias possibilidades de desdobramento, aplicação e pesquisa em diferentes contextos da Universidade e da comunidade por ela assistida, tais como o Serviço Materno-infantil do Hospital Universitário, a Creche UFF, o Serviço de Psicologia Aplicada, Escolas, Juizados da Infância e Adolescência e Conselhos Tutelares, 
privilegiando, deste modo, uma prática de intervenção interdisciplinar. Assim, através dos conhecimentos adquiridos na observação de bebês, e por sua pioneira inserção no espaço universitário, esperamos estar contribuindo para o desenvolvimento de uma sociedade mais humanizada.

\section{Discussão}

O grupo de trabalho Interação Pais-Bebê-Criança da Associação Nacional de Pesquisa e Pós-Graduação em Psicologia ANPEPP surgiu a partir do interesse comum de pesquisadores e coordenadores de grupos de pesquisas, baseados na importância das interações primárias no processo de desenvolvimento humano. Sobre esse pressuposto subjaz a proposta de articulação de perspectivas que aqui é apresentada. Mais além, outros pontos em comum podem ser identificados e serão discutidos, mas as diferenças de perspectivas garantem uma riqueza que pode contribuir para discussões que facilitem a co-construção de conhecimentos na área.

A primeira fonte de aproximação entre os autores é seu engajamento na pesquisa no campo da interação mãebebê/criança. Cada um explicita a perspectiva que orienta seus trabalhos e desenvolve procedimentos metodológicos coerentes com sua perspectiva específica. Três perspectivas teóricas principais são adotadas: a coconstrutivista, sócio-histórica ou sociocultural e sóciocognitivista; a etológico-evolucionária da teoria do apego; e a psicanalítica. É interessante notar que não há incompatibilidade entre as três perspectivas em relação à valorização da interação no processo de desenvolvimento. Com pressupostos diversos, busca-se explicar o papel da interação mãe/criança, tanto em geral, como na abordagem sociocultural e sócio-histórica, como das interações iniciais, nas abordagens etológico-evolucionária e psicanalítica. Além disso, verifica-se que diversos dos autores citados, buscam aproximações entre a Psicologia do Desenvolvimento e a Psicanálise, e que esta é possível e pode ser frutífera à semelhança dos estudos realizados por Stern (1985). Uma outra interlocução interessante é entre as visões clínicas e de pesquisa, levando ao desenvolvimento de procedimentos ou à utilização de alguns deles, de tradição clínica, na investigação do desenvolvimento e na formação profissional e de pesquisadores como é realizado pelo grupo de Chahon.

Alguns autores preocupam-se com a investigação das interações iniciais (grupos de Chaon, Piccinini, Batista Pinto, Seidl de Moura e Ribas, e Schermann). Outros focalizam etapas um pouco posteriores no ciclo vital (grupos de Bosa e Oliveira). Com a preocupação de compreender o processo de desenvolvimento em suas alterações, vários focalizam e desenvolvem estratatégias metodológicas para estudar interações em situações em que há risco e descontinuidade (p.ex. Schermann) ou transtornos como do autismo (p. ex. Bosa).

A definição de interação não é consensual, entretanto, embora se verifique uma tendência a considerar explicitamente a questão da ação recíproca, da coconstrução e da bidirecionalidade (grupos de Oliveira; Batista Pinto; Seidl de Moura e Ribas; e Piccinini). Há um foco no comportamento manifesto, na ação recíproca em vários dos modelos de investigação (p. ex. nos grupos de Oliveira, Seidl de Moura e Ribas; e Schermann), mas há também o reconhecimento de que transações implícitas e representações são de importância fundamental e de que há necessidade de serem desenvolvidos procedimentos metodológicos rigorosos para estudá-las. Seidl de Moura e Ribas admitem que este é um desafio a superar, mas não apresentam ainda sugestões metodológicas nesse sentido. Piccinini e seu grupo vêm tentando incorporar dados de entrevistas com os pais para apreender pelo menos uma parte desse processo implícito. O mesmo é feito pelos grupos de Batista Pinto e Chaon, embora utilizando-se de outros procedimentos. Nesse sentido a Psicanálise representa uma contribuição importante, porque considera que as interações envolvem não só características manifestas das pessoas envolvidas (diversos adultos e bebê ou criança), mas, também, elementos representacionais imaginários e fantasmáticos diversos.

Assim, além de categorias de "interação comportamental e afetiva", é incluída a análise da "interação fantasmática” (grupo de Batista Pinto). A questão das categorias de análise nos estudos de interação é uma outra contribuição interessante deste trabalho. Observa-se que, embora não utilizada de forma exclusiva, a observação é um recurso amplamente utilizado e que a maioria dos autores apresentam protocolos, sistemas ou roteiros de observação e codificação das observações em que categorias observacionais são meticulosamente apresentadas e definidas. Uma exceção é o trabalho do grupo de Chaon, que, com base em seus pressupostos, defende uma postura de "atenção flutuante" e ausência de definição de categorias a priori. Os demais trabalhos baseiamse no uso de categorias seja de comportamentos maternos ou de outro adulto, de bebês ou de crianças, ou ainda de interação, ou de ambos. Apenas Seidl de Moura e Ribas, seguindo os pressupostos da abordagem que adotam, incluem categorias de observação do contexto em que se dão as instâncias de interação focalizadas.

Nos procedimentos de observação predomina o registro por intervalos (de 5, 15 ou 30 segundos), utilizado 
com variações. Confirmando uma tendência da literatura de adequar o procedimento ao problema específico estudado, as sessões de observação são realizadas tanto no ambiente natural, nas casas das famílias ou nos hospitais (UTI Neonatal), quanto no laboratório, em situações propostas pelos investigadores (p. ex. grupo de Bosa, Oliveira; e Piccinini). Quando necessário, engenhosas situações são desenvolvidas e propostas, como nos estudos do grupo de Oliveira. As sessões são em geral de curta duração, seja por razões técnicas, ou em função das características das etapas do desenvolvimento dos bebês ou das crianças observadas (com exceção dos grupos de Batista Pinto e Chaon) .

Tal como advertido inicialmente, a pretensão deste trabalho de co-construção é modesta. Busca-se, principalmente, apresentar perspectivas e discutir suas aproximações e diferenças, visando demonstrar a complexidade e a falta de uma abordagem única e consensual às interações pais-criança e seu papel no desenvolvimento. Entretanto, não há como ignorar a diversidade de "olhares" que levam à escolha de modos de investigação variados e coerentes com esses olhares. Em vez de ignorar, pode-se discutir de forma respeitosa as diferenças e buscar avançar na co-construção do conhecimento na área. Esta é a proposta do Grupo de Trabalho da ANPEPP do qual fazem parte os autores deste artigo. Espera-se que a continuidade das discussões leve ao avanço e aprimoramento das propostas aqui apresentadas e a sua articulação.

\section{Referências}

Acoca Trigano, H. (2000). La vidéo en psychiatrie: Entre la voix et le voir. Perspectives Psychiatriques, 39(2), 94-96.

Ainsworth, M. D. S., Bell, S. M. \& Stayton, D. J. (1974). Infant-mother attachment and social development. Em M. P. Richards (Org.), The introduction of the child into a social world (pp. 99-135). London, Cambridge University.

Ainsworth, M. D. S., Blehar, M. C., Waters, E. \& Wall, S. (1978). Patterns of attachment: A psychological study of the Strange Situation. Hillsdale, New Jersey: Erlbaum.

Alfaya, C. (2000). Depressão materna e interação mãe-bebê em recém-nascidos pre-termo e a termo de risco. Dissertação de Mestrado não publicada, Psicologia Clínica. Pontifícia Universidade Católica do Rio Grande do Sul, Porto Alegre, RS.

Alvarenga, P. (2000). Práticas educativas maternas e problemas de comportamento na infância. Dissertação de Mestrado não-publicada, Curso de PósGraduação em Psicologia do Desenvolvimento, Universidade Federal do Rio Grande do Sul. Porto Alegre, RS.

Bakeman, R. \& Gottman, J. M. (1986). Observing interaction: An introduction to sequential analysis. Cambridge: Cambridge University Press.

Baltes, P. \& Staudinger, U. M. (1996). Interactive minds in a life span perspective: Prologue. Em P. Baltes \& U. M. Staudinger (Orgs.), Interactive minds: Life span perspectives on the social foundations of cognition (pp. 1-32). Cambridge: Cambridge University.
Bates, E., Camaioni, L., \& Volterra, V. (1979). The acquisition of performatives prior to speech. Em E. Ochs \& B. Schieffeling (Orgs.), Developmental pragmatics (pp. 111-128). London: Academic Press.

Batista, C. G. (1996). Observação do comportamento. Em L. Pasquali (Org.), Teoria e método de medida em ciências do comportamento (pp. 263-304). Brasília, Laboratório de Pesquisa em Avaliação e Medida/Instituto de Psicologia/UnB: INEP.

Batista Pinto, E., Vilanova, L. C. P. \& Vieira, R. M. (1997). O desenvolvimento do comportamento da criança no primeiro ano de vida: Padronização de uma escala para a avaliação e o acompanhamento. São Paulo, FAPESP: Casa do Psicólogo.

Batista Pinto, E. (2000) Psicoterapia breve mãe/bebê. Em C. F. Rohenkohl (Org.), A clínica com o bebê. (pp. 125-130). São Paulo: Casa do Psicólogo.

Belsky, J. (1986). A tale of two variances: Between and within. Child Development, 56, 1301-1305.

Bick, E. (1964). Notes on infant observation in psychoanalytic training. International Journal of Psychoanalysis, 45, 558-566.

Bick, E. (1968). The experience of the skin in early object relations. International Journal of Psychoanalysis, 49, 484-486.

Blurton Jones, N. (1981). Aspectos comparativos do contato mãe-criança. Em N. Blurton-Jones. (Org.), Estudos etológicos do comportamento da criança (pp. 317-340). São Paulo: Pioneira.

Bosa, C. (1998). Affect, social communication and self-stimulation in children with and without autism: A systematic observation study of requesting behaviours and joint attention. Dissertação de doutorado não-publicada. Institute of Psychiatry, Universidade de Londres. Londres, Inglaterra.

Bosa, C. (No prelo). Atenção compartilhada e identificação precoce do autismo. Psicologia: Reflexão e Crítica.

Bosa, C. A. \& Piccinini, C.A. (1994). Temperamento infantil e o apego mãe-criança: Algumas considerações teóricas. Psicologia: Teoria e Pesquisa, 10,193-212.

Bowlby, J. (1982). Formação e rompimento dos laços afetivos. São Paulo: Martins Fontes.

Bowlby, J. (1984). Apego e perda: Apego. Vol 1. São Paulo: Martins Fontes. (Original publicado em 1969).

Brazelton, T. B. (1962). Crying in infancy. Pediatrics, 29, 94-107.

Brazelton, T.B.(1974). The origins of reciprocity. Em m.Lewis \& L.A. Rosemblum (Orgs.), The effect of the infant on its caregiver (pp.49-76).New York : Wiley.

Brazelton, T. B. (1981). Comportement et compétence du nouveau-né. Psychiatrie de L'enfant, 24(2), 375-396.

Brazelton, T. B. (1988). O desenvolvimento do apego: Uma família em formação. Porto Alegre: Artes Médicas.

Brazelton, T. B. \& Als, H. (1981). Quatre stades précoces au cours du développement de la relation mère-nourisson. Psychiatrie de L'enfant, 24(2), 397-418.

Brown, A. L. \& Ferrara, R. A. (1985). Diagnosing zones of proximal development. Em J. V. Wertsch (Org.), Culture, communication, and cognition (pp. 273-305). New York: Cambridge University.

Bruner, J. (1996). The culture of education. Cambridge: Harvard University.

Buarque de Holanda, A. (1994). Novo Dicionário da Lingua Portuguesa (versão eletrônica). Rio de Janeiro: Nova Fronteira.

Caron, N. A. (1995). Fundamentos teóricos para a aplicação do método de E. Bick. Revista Brasileira de Psicanálise, 29, 283-291.

Carpenter, M., Nagell, K. \& Tomasello, M. (1998). Social cognition, joint attention and communicative competence from 9 to 15 months of age. Monographs of the Society for Research in Child Development, 63(4).

Carvalho, A. M. A. (1988). Algumas reflexões sobre o uso da categoria "interação social”. Anais da XVIII Reunião Anual de Psicologia (pp. 511-516). Ribeirão Preto, São Paulo.

Cole, M. (1998). Cultural psychology: A once and future discipline. Cambridge: The Belknap Press of Harvard University.

Couto Rosa, J. A. (1995). Reflexões sobre o método da observação da relação mãe-bebê. Revista Brasileira de Psicanálise, 29, 299-305. 
Cramer, B. (1974). Interaction réelle et interaction fantasmatique. Réflexion au sujet des thérapies et des observations du nourisson. Psychothérapies, $1,39-47$.

Cramer, B. (1985). Psychothérapies du nourrisson. Em S. Lebovici, R. Diatkine \& M. Soulé (Orgs.), Traité de psychiatrie de l'enfant et de l'adolescent (Vol. 2, pp. 689-694). Paris: PUF

Cramer, B. (1987). Objective and subjective aspects of parent-infant relations: an attempt at correlation between infant studies and clinical work. Em J. D. Osofsky (Org.), Handbook of infant development (pp. 10371057). New York: John Wiley.

Cramer, B. (1988). Psycbiatrie du bébé, nouvelles frontières. Paris/Genève: Eshel.

Cramer, B. (1997). Segredos femininos: De mãe para filha. Porto Alegre: Artes Médicas.

Cramer, B. (1999). A técnica das terapias breves pais/crianças pequenas. Em A. Guedeney \& S. Lebovici (Orgs.), Intervencões psicoterápicas pais/ bebê (pp. 91-99). Porto Alegre: Artes Médicas.

Cramer, B. \& Palacio-Espasa, F. (1993). Técnicas psicoterápicas mãe/ bebê: Estudos clínicos e técnicos. Porto Alegre: Artes Médicas.

Elbers, E., Maier, R., Hoekstra, T. \& Hoogsteder, M. (1992). Internalization and adult-child interaction. Learning and Instruction, 2, 101-118.

Fagundes, A. J. (1985). Descrição, definição e registro do comportamento. São Paulo: Edicom.

Field, T. (1987). Interaction and attachment in normal and atypical children. Journal of Consulting Clinical Psychology, 55, 853-859.

Fivaz-Depeursinge, E. \& Büngin, D., Corboz-Warnery, A., Lebovici, S., Stern, D., Byng-Hall, J., Lamour, M. (1994). The dynamics of interfaces: Seven authors in search of encounters across levels of description of an event involving a mother, father, and baby. Infant Mental Health Journal, 15, 69-89.

Fraiberg, S. (1980). Clinical studies in infant mental health: The first year of life. New York: Basic Books.

Fraiberg, S., Adelson, E. \& Shapiro, V. (1976). Ghosts in the nursery: A psychoanalytic approach to the problems of impaired mother-infant relationships. Journal of the American Academy of Child Psychiatry, 14, 387421.

Freud, S. (1905). Três ensaios sobre a teoria da sexualidade. Edição standard brasileira das obras psicológicas completas, VII (pp. 123-252), Rio de Janeiro: Imago.

Freud, S. (1909). Análise de uma fobia em um menino de cinco anos. Edição standard brasileira das obras psicológicas completas, $X$ (pp. 13-154), Rio de Janeiro : Imago.

Freud, S. (1914). A história do movimento psicanalítico. Edição standard brasileira das obras psicológicas completas, XIV (pp. 13-119), Rio de Janeiro: Imago.

Golse, B. (1998). Attachement, modèles opérants internes et métapsychologie, ou comment ne pas jeter l'eau du bain avec le bébé. Em A. Braconnier \& J. Sipos (Orgs.), Le bébé et les interactions précoces (pp. 149165). Paris: PUF.

Guedeney, A. \& Lebovici, S. (1999). Intervenções psicoterápicas pais/bebê. Porto Alegre: Artes Médicas.

Houzel, D. (1995). Observação de bebês e psicanálise: Ponto de vista epistemológico. Em M-B. Lacroix \& M. Monmayrant (Orgs), A observação de bebês: Os laços do encantamento (pp. 87-94). Porto Alegre: Artes Médicas.

Isabella, R. A., Belsky, J. \& Von Eye, A. (1989). Origins of infant-mother attachment: An examination of interactional synchrony during the infant's first year. Developmental Psychology, 25, 12-21.

Izard, C. E. (1993). The psychology of emotions. New York: Plenum.

Izard, C. E. (1996). Innate and universal facial expressions: Evidence from developmental and cross-cultural research. Psychological Bulletin, 115, 288-299.

Kuhn, T. (1987). A estrutura das revoluções científicas. São Paulo: Perspectiva. (Original publicado em 1970)

Lebovici, S. (1983). Le bébé, la mère et le psychanalyste: Les interactions precoces. Paris: Le Centurion.

Lebovici, S. (1992). La théorie de l'attachement et la métapsychologie freudienne. Devenir, 4(4), 33-48.
Lebovici, S. (1994). L’homme dans le bébé. Revue Francaise de Psychanalyse, LVIII (3), 661-680.

Lebovici, S. (1998). Lettre ouverte à Robet Emde et réponse à ses questions concernant l'empathie. Em A. Braconnier \& J. Sipos (Orgs.), Le bébé et les interactions précoces (pp. 9-26). Paris: PUF

Lopes, R. C. S. \& Piccinini, C. A. (1992). Procedimentos metodológicos da pesquisa em apego: Problemas e perspectivas. Psicologia: Reflexão e Crítica, 5, 79-90.

Marfo, K. (1990). Maternal directiveness in interactions with mentally handicapped children: An analytical commentary. Journal of Child Psychology and Psychiatry, 31, 531-549.

Mazet, P. (1999). El aporte de las interacciones precoces e la comprension de las primeras relaciones padres-hijo. Em A. Barriguete, P. Cardenes \& B. Golse (Orgs.), Adopción en el siglo XXI: Actualidades en el estudio mutidisciplinario de la adopción (pp.69-78) México: DIF

Mazet, P., Cukier-Hemeury, F., Latoch, J., Rosenblun, O. \& Sitbon, H. (1989). Étude historique et critique. Em S. Lebovici, P. Mazet \& J. P. Visier (Orgs.), L'évaluation des interactions précoces entre le bébé et ses partenaires (pp. 15-39). Paris: Eshel.

Mazet, P. \& Stoleru, S. (1990). Manual de psicopatologia do recém-nascido. Porto Alegre: Artes Médicas.

Mélega, M. P. (1995). A supervisão da observação da relação mãe-bebê: Ensino e investigação. Revista Brasileira de Psicanálise, 29, 263-280.

Nogueira, A. L. H. (1993). Eu leio, ele lê, nós lemos: Processos de negociação na construção da leitura. Em A. L. B. Smolka \& M. C. A. R. Goes (Orgs.), A linguagem e o outro no contexto escolar: Vygotsky e a construção do conbecimento (pp. 15-33). Campinas: Papirus.

Oliveira, E. A. de (2000). Cognições sociais maternas e interação mãecriança. Em Associação Nacional de Pesquisa e Pós-Graduação em Psicologia (Orgs.), Anais do VIII Simpósio de Pesquisa e Intercâmbio Científico da ANPEPP (pp. 43). Campinas, PUC: ANPEPP.

Pellegrini, A. D. (1996). Observing children in their natural worlds: A methodological primer. New Jersey: Lawrence Erlbaum.

Piatelli-Palmarini, M. (Org.). (1980). Language and learning: The debate between Jean Piaget and Noam Chomsky. London \& Henley: Routledge and Keagan Paul.

Repp, A., Harman, M., Felce, D., Acker, R., \& Karsh, K. (1989). Conducting behavioural assessment on computer-collected data. Behavioural Assessment, 11, 249-268.

Robert-Tissot, C. (1989). Le questionnaire "Symptom Check-List". Em S. Lebovici, P. Mazet \& J. P Visier (Orgs.), L'évaluation des interactions précoces entre le bébé et ses partenaires (pp. 179-186). Paris: Eshel.

Robson, C. (1993). Real world researcb: A resource for social scientists and practitionerresearchers. Cambridge: Blackwell.

Rogoff, B. (1998). Observando a atividade sociocultural em três planos: Apropriação participatória, participação guiada e aprendizado. Em J. V. Wertsch, P. del Río \& A. Alvarez (Orgs.), Estudos socioculturais da mente (pp. 123-142). Porto Alegre: Artes Médicas.

Rogoff, B. \& Chavajay, P. (1995). What's become of research on the cultural basis of cognitive development. American Psychologist, 50(10), 859-877.

Seidl de Moura, M. L. (1999). Interação mãe-bebê e o desenvolvimento infantil: Um estudo longitudinal e transcultural. Projeto de Pesquisa. Universidade do Estado do Rio de Janeiro. Rio de Janeiro, RJ.

Schermann, L. (1986). Interação materno-filial: Estudo longitudinal (de 0 a 6 meses) com pares mãe-criança de crianças prematuras e a termo. Tese de Doutorado não publicada. Curso de Pós-Graduação em Psicologia Clínica, Pontifícia Universidade Católica de São Paulo. São Paulo, SP.

Schermann, L., Bohlin, G. \& Hagekull, B. (1994). Interaction of mother and preterm infant at 34 weeks postconceptional age. Early Development and Parenting, 3(3), 171-180.

Schermann, L., Hagekull, B., Bohlin, G., Persson, K. \& Sedin, G. (1997). Interaction of mothers and infants born at risk during the first 6 months of corrected age. Acta Paediatrica, 86, 864-872.

Schermann, L. (1999). Observação do comportamento social. Psico, 30(2), 95-102. 
Smiley, P. A. \& Dweck, C. S. (1994). Individual differences in achievement goals among young children. Child Development, 65, 1723-1743.

Shuttleworth, J. (1995). A relação entre os métodos e modelos da psicanálise e os da psicologia do desenvolvimento. Revista Brasileira de Psicanálise, 29, 219-234.

Smolka, A. L. B. (1993). A dinâmica discursiva no ato de escrever: Relações oralidade-escritura. Em A. L. B. Smolka, \& M. C. A. R Góes (Orgs.), A linguagem e o outro no contexto escolar: Vygotsky e a construção do conbecimento (pp. 35-63). Campinas: Papirus.

Sperb, T. M. (1999, Maio). Interação adulto-criança e desenvolvimento infantil em diferentes contextos. Trabalho apresentado no I Congresso NorteNordeste de Psicologia e V Semana Baiana de Psicologia. Salvador: UFBA.

Spitz, R. A. (1998). O primeiro ano de vida. São Paulo: Martins Fontes. (Original publicado em 1965)

Stern, D. N. (1977). The first relationship infant and mother. Cambridge: Harvard University.

Stern, D. N. (1985). The interpersonal world of the child. A view from psychoanalysis and developmental psychology. New York: Basic Books.

Stern, D. (1992). O mundo interpessoal do bebê. Porto Alegre: Artes Médicas.

Stern, D. N. (1997). A constelação da maternidade: O panorama da psicoterapia pais/ bebê. Porto Alegre: Artes Médicas.

Stern, D.N., Robert-Tissot, C., De Muralt, M. \& Cramer, B. (1989). Le KIAProfil: Un instrument de recherche clinique pour l'evaluation des états affectifs du jeune enfant. Em S. Lebovici, P. Mazet \& J. P. Visier (Orgs.), L'évaluation des interactions précoces entre le bébé et ses partenaires (pp.151-160). Paris: Eshel.
Terigi, F. \& Baquero, R. (1997). Repensando o fracasso escolar pela perspectiva psicoeducativa. Em A. Abramowicz \& J. Moll (Orgs.), Para além do fracasso escolar (pp. 105-126). Campinas: Papirus.

Trevarthen, C. (1996). Communicating and plaving with an autistic child. Em C. Trevarthen, K. Aitken, D. Papoudi \& J. Robarts (Orgs.), Children with autism: Diagnosis and interventions to meet their needs (pp. 98-115). London: Jessica Kingsley.

Tronick, E. Z. (1989). Emotions and emotional communication in infants. American Psychologist, 44, 112-119.

Vasconcellos, V. M. R. \& Valsiner, J. (1995). Perspectiva co-construtivista na psicologia e na educação. Porto Alegre: Artes Médicas.

Vibbert, M. \& Bornstein, M. H. (1989). Specific associations between domains of mother-child interaction and toddler referential language and pretense play. Infant Behavior and Development, 12, 163-184.

Vygotsky, L. S. (1978). Mind in society: The development of higher psychological processes. Cambridge, MA: Harvard University.

Wendland-Carro, J., Piccinini, C. A. \& Millar, W. S. (1999). The role of an early intervention on enhancing the quality of mother-infant interaction. Child Development, 70, 713-721.

Wertsch, J. V. (1991). A sociocultural approach to socially shared cognition. Em L. B. Resnick, J. M. Levine \& S. D. Teasley (Orgs.), Perspectives on socially shared cognition (pp. 85-100). Washington, DC: American Psychological Association.

Recebido: 18/04/2001

Revisado: $15 / 05 / 2001$

Aceite Final: 08/06/2001

Sobre os autores:

Cesar Augusto Piccinini é Psicólogo, Doutor em Psicologia pela University of London, Pesquisador do CNPq, Professor da Universidade Federal do Rio Grande do Sul.

Maria Lucia Seidl de Moura é Psicóloga, Doutor em Psicologia Cognitiva pela Fundação Getúlio Vargas, Pesquisador do CNPq, Professor Titular do Instituto de Psicologia, Programa de PósGraduação em Psicologia Social da Universidade do Estado do Rio de Janeiro, e Presidente da Associação Nacional de Pesquisa e Pós Graduação em Psicologia (ANPEPP).

Adriana Ferreira Paes Ribas é Doutoranda da Universidade do Estado do Rio de Janeiro.

Cleonice A. Bosa é Psicóloga, Mestre em Psicologia do Desenvolvimento/UFRGS; Doutora em Psicologia pelo Instituto de Psiquiatria - Universidade de Londres/UK; Profa. Adjunto do PPG em Psicologia do Desenvolvimento/UFRGS

Ebenézer A. de Oliveira é Teólogo pelo Seminário Presbiteriano do Norte, Recife/PE, e Bacharel em Ciência pelo Philadelphia College of Bible. Estudou psicologia na Temple University. É Mestre em Aconselhamento/Religião pelo Westminster Theological Seminary e em Psicologia Escolar pela Universidade de Delaware. Obteve o Ph.D. em Desenvolvimento Humano Aplicado pela Universidade de Delaware e é Associate Professor no Departamento de Psicologia do Malone College, Ohio, E.U.A. Elizabeth Batista Pinto é Professora da Universidade de São Paulo.

Ligia Schermann é Psicóloga, Doutora em Psicologia pela Pontifícia Universidade Católica de São Paulo, Professora do Programa de Pós-Graduação em Saúde Coletiva da Universidade Luterana do Brasil, campus Canoas.

Vera Lúcia Chahon é Psicóloga, Mestre em Psicologia Aplicada/PUC-RJ, Professora da Universidade Federal Fluminense. 


\section{Grupo de Pesquisa em Interação Social Desenvolvimento e Psicopatologia \\ - GIDEP -}

O objetivo do GIDEP é produzir conhecimentos para a teoria e prática na área de desenvolvimento e psicopatologia. Em particular, busca-se investigar os fatores socioemocionais e cognitivos no desenvolvimento normal e atípico dentro do contexto de interações pais-criança, criança-criança, e adolescente-família. O GIDEP está empenhado na qualificação de pesquisadores e profissionais dentro de uma perspectiva interdisciplinar. $\mathrm{O}$ GIDEP constitui-se em um dos Grupos de Pesquisa do CNPq/UFRGS. Sete teses e 39 dissertações foram defendidas ou estão em orientação no Grupo.

Participantes e linhas de pesquisa

Cesar A. Piccinini (PhD pela University of London): Interação pais-bebê/criança; Apego e temperamento infantil; Estratégias educativas parentais.

Tânia M. Sperb (PhD pela University of London): Interação de crianças; Cultura e desenvolvimento; Narrativas, desenvolvimento e psicopatologia.

Rita Sobreira-Lopes (PhD pela University of London): O desenvolvimento sócioafetivo no contexto das relações familiares; relações pais-filhos em momentos de transição; Desenvolvimento da autonomia na família.

Participam ainda do grupo um técnico de audiovisual, 07 Doutorandos, 10 Mestrandos, e 09 Bolsistas de Iniciação Científica.

Infra-estrutura do GIDEP: O Grupo mantém o Laboratório de Observação de Processos Interativos equipado com sofisticados equipamentos de gravação, digitalização e edição de imagens de vídeo, o que possibilita análises sistemáticas das observações gravadas.

Contatos internacionais e convidados pelo Grupo: Artin Goncu (EUA/1993); Annette Watilon (Bélgica/1997); Jan Valsiner (EUA/1995); Jonathan Tudge (EUA/desde 1994); Marc Bigras (Canadá/1999); Palácio Espasa (Suiça/1997); Stuart Millar (Inglaterra/ desde 1996).

\section{Endereço:}

GIDEP/CPG Psicologia/UFRGS

Rua Ramiro Barcelos, 2600

90035.003, Porto Alegre, RS

Fone: (51) 33309507 